\title{
BMJ Open Measuring the efficiency of health systems in Asia: a data envelopment analysis
}

\author{
Sayem Ahmed, ${ }^{\oplus 1,2,3}$ Md Zahid Hasan, ${ }^{\oplus 1}$ Mary MacLennan, ${ }^{4}$ Farzana Dorin, ${ }^{1}$ \\ Mohammad Wahid Ahmed, ${ }^{1}$ Md Mehedi Hasan, ${ }^{5}$ Shaikh Mehdi Hasan, ${ }^{1}$ \\ Mohammad Touhidul Islam, ${ }^{6}$ Jahangir A M Khan ${ }^{2,3}$
}

To cite: Ahmed S, Hasan MZ, MacLennan $\mathrm{M}$, et al. Measuring the efficiency of health systems in Asia: a data envelopment analysis. BMJ Open 2019;9:e022155. doi:10.1136/ bmjopen-2018-022155

- Prepublication history and additional material for this paper are available online. To view these files, please visit the journal online (http://dx.doi. org/10.1136/bmjopen-2018022155).

Received 5 February 2018 Revised 1 December 2018 Accepted 8 January 2019
Check for updates

(C) Author(s) (or their employer(s)) 2019. Re-use permitted under CC BY-NC. No commercial re-use. See rights and permissions. Published by BMJ.

For numbered affiliations see end of article.

Correspondence to

Sayem Ahmed;

sayemahmed@icddrb.org

\section{ABSTRACT}

Objective This study aims to estimate the technical efficiency of health systems in Asia.

Settings The study was conducted in Asian countries. Methods We applied an output-oriented data envelopment analysis (DEA) approach to estimate the technical efficiency of the health systems in Asian countries. The DEA model used per-capita health expenditure (all healthcare resources as a proxy) as input variable and cross-country comparable health outcome indicators (eg, healthy life expectancy at birth and infant mortality per 1000 live births) as output variables. Censored Tobit regression and smoothed bootstrap models were used to observe the associated factors with the efficiency scores. A sensitivity analysis was performed to assess the consistency of these efficiency scores.

Results The main findings of this paper demonstrate that about $91.3 \%$ (42 of 46 countries) of the studied Asian countries were inefficient with respect to using healthcare system resources. Most of the efficient countries belonged to the high-income group (Cyprus, Japan, and Singapore) and only one country belonged to the lower middle-income group (Bangladesh). Through improving health system efficiency, the studied high-income, upper middle-income, low-income and lower middle-income countries can improve health system outcomes by $6.6 \%, 8.6 \%$ and $8.7 \%$, respectively, using the existing level of resources. Population density, bed density, and primary education completion rate significantly influenced the efficiency score.

Conclusion The results of this analysis showed inefficiency of the health systems in most of the Asian countries and imply that many countries may improve their health system efficiency using the current level of resources. The identified inefficient countries could pay attention to benchmarking their health systems within their income group or other within similar types of health systems.

\section{BACKGROUND}

In Asia, there are approximately 4.4 billion people spread across highly diverse countries, from economic powerhouses like China and Singapore to poorer economies such as Laos, Cambodia and Myanmar. ${ }^{1}$
Strengths and limitations of this study

- Data envelopment analysis was used to determine the extent of inefficiency in health systems across Asia.

- We extracted health systems level indicators from the widely used World Bank World Development Indicators database and the WHO Open Data Repository.

- Due to data unavailability, we used health system outcomes in addressing the health systems efficiency rather than true health system output.

Overall, the continent is often cited as the fastest growing and most dynamic region in the world. Over the past number of years, Asian societies have also made impressive progress in ensuring better healthcare services, especially those targeted towards improving maternal and infant health and increasing life expectancy. ${ }^{2}$ However, whether economic gains have translated to efficient health systems across the region is still not well studied.

It is important that the healthcare resources in Asia are used efficiently. In Asia, generally government spending on healthcare is low compared with total health expenditure, and it is often not focused on those who need it most. ${ }^{3}$ For example, in the South Asia region, governments spend $31 \%$ of total health expenditure, which is about $1 \%$ of gross domestic product (GDP). ${ }^{45}$ In many Asian countries, personal health expenses or out-of-pocket payments are a major cause of poverty. ${ }^{16}$ For instance, from a study of 11 Asian countries, it was found that 78 million people are pushed into poverty due to out-of-pocket spending for healthcare. ${ }^{7}$ Ageing populations and non-communicable diseases that are often preventable but expensive to treat (eg, diabetes and cancers linked to tobacco) 
impose and will continue to impose heavy costs on households and public health budgets. Moreover, a major challenge for Asian countries is the control and prevention of different communicable diseases (eg, HIV/AIDS, tuberculosis and polio) due to the movement of people across borders and the exchange of goods. ${ }^{8}$

In light of this, it is very important that the health systems of these countries are efficient in using their resources. The WHO has estimated that due to inefficiency about $20 \%-40 \%$ of total healthcare resources are being wasted per year among its member countries. Furthermore, this rate is higher in low-income and middle-income countries. ${ }^{9}$ In Asia, the variation in efficiency across income groups and contexts can perhaps lead to lessons learnt in addressing it. In order to address inefficiency, Asia's health systems can look towards different dimensions of performance such as their effectiveness, efficiency, access, equity and quality. ${ }^{10} \mathrm{~A}$ great deal of practitioner and academic literature have analysed the relationship between the efficient production of health services and universal health coverage as well as the widespread importance of measuring overall health system performance. ${ }^{911}$

Assessing the efficiency of healthcare systems is a difficult process as analyses often encounter methodological problems, particularly due to the need for appropriate and valid outcome indicators. ${ }^{12}$ Despite the empirical difficulties in applying efficiency concepts to health systems, efficiency can be measured on both micro and macro levels. ${ }^{13}$ Measuring health system efficiency at a macro level is particularly important in order to understand health system performance across the globe and take required action to minimise inefficiency. ${ }^{11} 14$

A number of studies have analysed the healthcare efficiency in the Americas, ${ }^{15}{ }^{16}$ Western Europe ${ }^{17} 18$ and Asia ${ }^{1920}$ to shed light on the efficiency of different national healthcare systems. A systematic review on measuring efficiency related to several aspects of healthcare performed by Hollingsworth et al. ${ }^{21}$ Dimas et $a l^{22}$ evaluated the productivity of Greek public hospitals and found that productivity changes were dominated by technical change. Additionally, Zere et al ${ }^{23}$ measured the technical efficiency and productivity of hospitals in South Africa and examined the impact of hospital characteristics on efficiency and productivity. ${ }^{23}$

Several studies have reported on different determinants of health system efficiency. For example, a study conducted in China reported that GDP per capita, proportion of primary health worker and population density were the key determinants of the efficiency in Chinese health system. ${ }^{24}$ Another study in the Canadian context reported that readmission, obesity and smoking and average income of the population are key determinants of health system efficiency. ${ }^{25}$

In an international study of efficiency in 170 Asian and non-Asian countries, it was observed that Asian countries were comparatively in the middle with respect to health system efficiency scores. ${ }^{26}$ This indicates that there is room for improvement to optimise health benefits from the available health sector resources. In this region, a number of studies have been conducted at the country level to address health systems efficiency, ${ }^{27} 28$ but cross-country comparison of the health system efficiency is limited. ${ }^{29}$

Asian countries are not homogeneous in terms of area, population and economic conditions; however, they have public health functions and a number of their health system outcomes are in common. ${ }^{30}$ Many of the countries share similar health systems problems, including a high burden of diseases due to the geographical contiguity, disease patterns and social conditions and inadequate resources for healthcare. Understanding health systems efficiency in different Asian countries could promote shared learning and highlight key areas of best practice, as well as areas where improvement is needed. Furthermore, given geographical proximity and many strong relationships experienced with nearby countries, there is likely to be relative ease in the ability to practically understand, learn and apply nuance about healthcare systems from one country to another.

A study on the efficiency of health systems in this region will help to provide lessons through comparison across countries. This paper aims to achieve this goal through measuring the technical efficiency and scale efficiency of the healthcare systems of selected Asian countries.

\section{METHODS}

This study employed two stages of efficiency analysis using cross-sectional data. In the first stage, data envelopment analysis (DEA) was used to estimate the country efficiency scores. In the second stage, a regression analysis and a bootstrap method were employed to identify the factors associated with the health system efficiency. The software package STATA V.13 was used for all of the analyses.

\section{Data sources}

We used two main data sources: the WHO Data Repository $^{31}$ and World Development Indicators-2015 (WDI). According to the list of United Nations Statistics Division, there are 50 Asian countries and territories. Among these, 46 were used for this study. ${ }^{32}$ Four countries and territories (Hong Kong, North Korea, Macao, and West bank and Gaza) were excluded due to missing data of selected variables in the WDI database. ${ }^{5}$ However, selected variables for the study countries were not reported in WDI for every year. This problem is unavoidable in studies based on WDI data. ${ }^{33-35}$ Earlier studies adopted two approaches to deal with such problem. First, they used a value from a slightly earlier year as in Anderson $e t a l^{33}$ and second, they used a smaller number of countries in the model as in Färe et $^{3 l^{34}}$ and Grubaugh and Santerre. ${ }^{35}$ Given the importance of including as many countries as 
possible to study technical efficiency using DEA, we opted for the first approach. However, to avoid missing variable, we used slightly earlier WDI statistics.

\section{Input and output variables}

A main assumption of the DEA model used in our analysis was that in Asian countries, the selected health outcomes are dependent on the inputs of healthcare resources. We selected the input variables as proxies for the quantity of inputs that a country devotes to healthcare (ie, health expenditure per capita) and outcome variables as the healthy life expectancy at birth (HALE) and infant mortality (per 1000 live births). The health expenditure per capita was extracted from the Global Health Expenditure database managed by the WHO. In this database, there are national health expenditure statistics for more than 190 WHO Member States in line with the new System of Health Accounts 2011 (SHA 2011) framework. The SHA 2011 framework was developed by Organisation for Economic Co-operation and Development (OECD) to rigorously track health expenditure (eg, by all financial sources, by all services) at the national level and to enable comparability across countries. The capital expenditure (eg, infrastructure) was included in the total health expenditure estimation. ${ }^{31}$ The relationship between health expenditure and outcomes considered here is consistent with the view that health expenditure has diminishing returns, or additional expenditure beyond a certain level has relatively smaller incremental effect on life expectancy or infant mortality ${ }^{36}$ To be clear, reduction in infant mortality and increase in life expectancy signify improvement in the health outcomes of a country. Some studies have included life expectancy at birth as an outcome variable $^{37-39}$; however, it is argued that quality of life matters as much as, if not more than, quantity of life, and therefore, life expectancy should be a weighted health quality measure. As a result, HALE has been incorporated as a proxy of health quality as the outcome of health systems. Also, it is important to note that instead of using the infant mortality directly in the DEA model, we used the inverse of infant mortality as the model assumes that inputs and outputs are isotonic (ie, increased input reduces efficiency as well as increased output increases efficiency). ${ }^{40}$ Without this correction, a higher infant mortality figure would have been said to incorrectly contribute to a better health system outcome.

\section{Data envelopment analysis}

DEA is a widely used non-parametric method that identifies an efficiency frontier by using linear programming techniques and the distance of each decision-making unit (DMU) to the frontier. Of the two types of efficiency analysis approach namely DEA and Stochastic Frontier Analysis, we choose DEA. The key advantage of the DEA approach in this analysis is that it can incorporate multiple inputs and outputs, which are measured in different units.
One type of DEA model, developed by Charnes, Cooper and Rhodes (CCR), assumes that production has constant returns to scale (CRS), meaning any change in the input will result in a proportionate change in the output. ${ }^{41}$ Another model proposed by Banker, Charnes and Cooper (BCC) assumes that production has variable returns to scale (VRS) implying an increase in the input will result in either an increase or a decrease in the output. The latter methodology is particularly useful for this study since it aims to measure the efficiency related to organisational units (ie, the health systems of different countries), which use numerous resources to produce multiple outputs and accommodate a more flexible assumption of VRS. ${ }^{26} 42$ This is more realistic and reflective of changes in the real world. ${ }^{27}$

We measured scale efficiency to see whether the health systems of Asian countries are operating at their optimal sizes or not. ${ }^{43}$ The size of health systems is a major political decision in Asian countries. To some extent, it depends on how the policy makers or government are prioritising health among other competing public services (eg, education, military and electricity) ${ }^{44}$ Scale efficiency scores provide information on the optimality of a DMU size; in this case, the health system of a country. When a production unit (DMU) operates at CRS, technical efficiency is equal to scale efficiency. However, when DMUs are not operating at optimum scale, technical efficiency measured with the CCR model may be altered by scale efficiency. The BCC model, which defines production through VRS, can incorporate the impact of scale efficiency in the measurement of technical efficiency. The scale efficiency is measured as the ratio of CRS technical efficiency scores and VRS technical efficiency scores. ${ }^{45}$

When it comes to DEA studies comparing countries, both the input-oriented and output-oriented models have been adopted for analysis. An output-oriented DEA model aims to maximise the outputs with a given amount of inputs, while input-oriented models focus on minimising the inputs used to obtain a certain amount of output. Many studies have been carried out using DEA to assess the efficiency of healthcare systems using the two approaches in both high-income and low-income countries. ${ }^{28}{ }^{46-48}$ In this study, an output-oriented DEA model was deemed more appropriate based on the premise that the input (ie, per capita expenditure) is likely to be less flexible. In other words, health system stewards are likely to have more leverage in controlling outputs through innovative programming and improvements in provided healthcare, rather than by increasing spending and resources.

\section{Output-oriented model}

The output-oriented technical efficiency model focuses on increasing output without changing the quantity of inputs used. The objective of the model for solving each particular DMU (health system) is to maximise the efficiency score (denoted $\phi$ ) meaning the amount by which 
all outputs can be improved for each country's health system under consideration while holding input constant.

The output-oriented DEA model is specified as follows:

$$
\operatorname{Max} \phi=\sum O_{r} Y_{r_{0}}+O_{0}
$$

Subject to constraints:

$$
\begin{gathered}
\sum_{i=1}^{m} V_{i}+X_{i j_{0}}=1 \\
\sum_{r=1}^{s} O_{r}+Y_{r j}-\sum V_{r} X_{i j}+O_{0} \leq 0, j=1, \ldots, n \\
O_{r}, V_{i} \geq 0 \\
O_{0}>0, \text { or } O_{0}=0 \text { or } O_{0}<0 ;
\end{gathered}
$$

where,

$Y_{\mathrm{ri}}=$ amount of output $\mathrm{r}$ from country $\mathrm{j}$.

$\mathrm{X}_{\mathrm{ij}}=$ amount of input $\mathrm{i}$ to country $\mathrm{j}$.

$\mathrm{O}_{\mathrm{r}}=$ weight given to output $\mathrm{r}$.

$\mathrm{V}_{\mathrm{i}}=$ =weight given to input $\mathrm{i}$.

$\mathrm{n}=$ number of countries.

$s=$ number of outputs.

$\mathrm{m}=$ number of inputs.

$\mathrm{O}_{0}>0$ defines increasing returns to scale, $\mathrm{O}_{0}=0$ defines CRS, and $\mathrm{O}_{0}<0$ defines decreasing returns to scale.

The technical efficiency scores is defined by $\phi$ and, it ranges between 0.00 and 1.00; if it is equal to 1.00 , then the production from the DMU is efficient; while if it is less than 1.00 , the DMU is inefficient.

\section{Explaining efficiency through regression analysis}

One of the limitations of the DEA approach is the serial correlation of the efficiency scores generated through this approach. In other words, the correlation between inputs and outputs, and consequently with the estimated efficiency scores resulted in this serial correlation. Thus, the scores of one DMU is not independent on that of the other DMUs. To handle this limitation, scholars such as Ramalho et $a t^{49}$ and McDonald ${ }^{50}$ have argued that econometric models like probit, logit and truncated regression (Tobit) can be used for second-stage analysis for identifying impact of environmental variables on efficiency. However, scholars such as Simar and Wilson ${ }^{51}$ have argued that the conventional statistical inferences are inappropriate in the second-stage regression due to the bias of the DEA score and recommend using bootstrap methods. ${ }^{51}$ Afonso and St. Aubyn ${ }^{52}$ showed in their empirical study that the censored normal Tobit regression and bootstrap algorithms yield very similar results. However, we have adopted both the Tobit model and smoothed bootstrap model in explaining the association with health system efficiency to be comprehensive.

The VRS efficiency scores computed using the DEA model were regressed against a few health service productions (eg, physician and beds density per 1000 population) and some environmental factors (table 1). Since, by definition, the DEA scores range between 0 and 1 , and some of the data tend to concentrate on these boundary values (ie, censored for the DMUs with a value at one), ordinary least squares cannot estimate the regression. Therefore, a Tobit model is suitable for such regression. For the convenience of calculation, we assumed a censoring point at zero in this model. As a result, the efficient DMUs will have a score of zero, and the inefficient DMUs will have score greater than zero. Following Zere, ${ }^{53}$ we applied this method by transforming VRS technical efficiency scores into VRS inefficiency scores and leaving censoring at 0 as follows.

$$
\text { Inefficiency score }=\left(\frac{1}{\text { VRS technical efficiency score }}\right)-1
$$

The Tobit regression model used variables representing access to healthcare and health status. Guided by several similar studies, physician density (the number of physicians per 1000 population) and bed density (the number of inpatient beds per 1000 population) were selected

\begin{tabular}{|c|c|c|c|c|c|c|}
\hline Characteristics/description & Mean & Median & SD & Minimum & Maximum & Source \\
\hline \multicolumn{7}{|l|}{ Input variable } \\
\hline Health expenditure per capita, PPP & 1133.71 & 663.94 & 1157.72 & 88.03 & 4405.13 & WDI \\
\hline \multicolumn{7}{|l|}{ Outcome variables } \\
\hline Healthy life expectancy at birth (years) & 64.29 & 65.2 & 5.1 & 53.2 & 75.9 & WHO \\
\hline Infant mortality (per 1000 live births) & 19.9 & 13.9 & 15.8 & 2.0 & 65.7 & WDI \\
\hline \multicolumn{7}{|l|}{ Explanatory variables for Tobit model } \\
\hline Physicians (per 1000 people) & 1.6 & 1.6 & 1.1 & 0.1 & 4.8 & WDI \\
\hline Hospital beds (per 1000 people) & 2.9 & 2.1 & 2.7 & 0.1 & 13.7 & WDI \\
\hline Smoking prevalence, males (\% of adults) & 42.2 & 42.2 & 10.5 & 18.9 & 71.8 & WDI \\
\hline Primary completion rate, total (\% of relevant age group) & 96.5 & 97.9 & 11.4 & 66.7 & 116.5 & WDI \\
\hline
\end{tabular}
as determinants of access to healthcare. ${ }^{35}$ In addition to healthcare, the health status of individuals is determined by the lifestyle and behaviours; therefore, we also included two environmental factors as determinants of

PPP, purchasing power parity; SD, standard deviation; WDI, World Development Indicators-2015. 

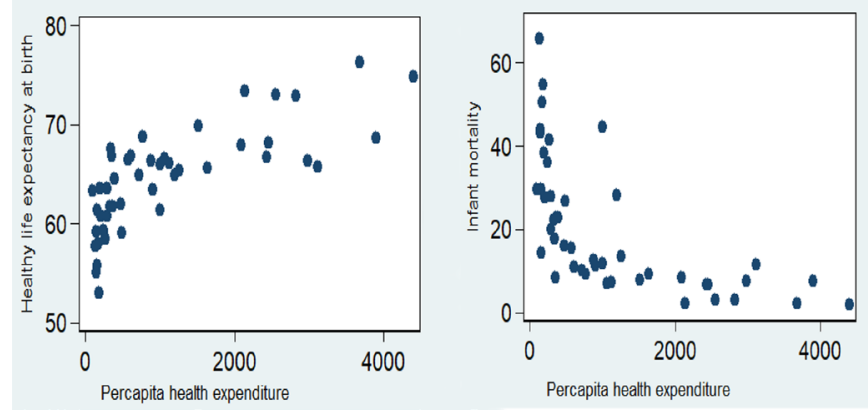

Figure 1 Association across health systems input and outcome.

efficiency, namely smoking prevalence among adult male (percentage of adults) and primary education completion rate of relevant age group. The relevant age group for the primary completion rate is defined as the number of new entrants (enrolments minus repeaters) in the last grade of primary education (regardless of age), divided by the population at the entrance age for the last grade of primary education of a country. ${ }^{55}$ The adverse health effect of smoking consequently affects health outcomes and also the health system efficiency. ${ }^{25} 5256$ Education is found to be an important factor in determining individual health status. Higher educational attainment is associated with higher income which, in turn, secures a healthy living environment and access to healthcare. ${ }^{57}$ Additionally, we included population density (population living per square kilometre of land area) as the control of efficiency. This is because population density can affect the quality of healthcare services.

The Tobit regression models were specified as follows:

$$
\text { Ineff }_{i}=\begin{aligned}
& \beta_{0}+\beta_{1} \text { Phy }_{i}+\beta_{2} \text { Beds }_{i}+\beta_{3} \text { Primary_ed }_{i}+ \\
& \beta_{4} \text { Smoking }_{i}+\beta_{5} \text { Inc }_{i}+\beta_{5} \text { Pop_density } \\
& i
\end{aligned}
$$

where,

Ineff=the technical inefficiency score; continuous variable.

Phy=physician density; categorical variable ( $1=$ fewer than one physician; $2=1-2$ physicians, $3=$ more than two physicians).

Beds=beds density; categorical variable $(1=$ fewer than one bed, $2=$ more than one to less than or equal to three beds, $3=$ more than three to less than or equal to five beds, $4=$ more than five beds).

Inc=income group of the country; categorical variable (1=low-and lower middle-income, 2=upper middle-income, 3 =high-income).

Pop_density=population density; categorical variable ( $1=$ fewer than or equal to $100,2=$ more than 100 to less than or equal to $200,3=$ more than 200).

Finally, $\varepsilon_{i}$ was the stochastic error term.

We submitted the initial DEA scores in a smoothed bootstrap method design by Simar and Wilson ${ }^{51}$ to estimate the robust efficiency score from the bootstrapped regression analysis to identify factors associated with these scores. The simarwilson command in STATA V.13 was applied in the analysis using externally estimated DEA scores (algorithm \#1). ${ }^{58}$

\section{Sensitivity analysis}

The efficiency scores can be affected by the number of inputs and outputs used in DEA in relation with the number of DMUs. The scores can be overestimated if the number of DMUs is relatively small compared with the number of inputs or very large compared with the number of inputs and outputs. ${ }^{596}$ It is suggested that the number of DMUs should be at least three times of the inputs and outputs variables. ${ }^{61}{ }^{62}$ In our model, the number of DMUs ${ }^{46}$ is more than three times of the number of inputs and outputs, ${ }^{9}$ and this is not a binding constraint for this study.

There is a possibility that choosing different variables in the DEA model may produce inconsistent results such as inconsistent efficiency estimate. There is no test to assess the suitability of a particular model specification in DEA. ${ }^{63}$ Therefore, we carried out a sensitivity analysis of the efficiency scores by running the DEA model several times using different combinations of input and outcome variables. Different specifications of the DEA models were considered (eg, dropping the efficient countries, using HALE at age 60 years as input, using health expenditure per capita at current US\$ as input, and excluding countries with any missing variable for the year 2015) for testing the sensitivity of our main model.

\section{Patient and public involvement}

The study used secondary data from WHO and WDI databases. No patients were involved in this study. Study findings will be shared with the stakeholders, including local community groups in community meetings and at national or regional conferences.

\section{RESULTS}

The descriptive statistics of the selected input, outcome and environmental variables are shown in table 1 . The per capita health expenditure ranges from a minimum of US $\$ 88.03$ (Bangladesh) to a maximum of US $\$ 4405.13$ (Japan) with a mean, median, and SD of 1133.71, 663.94 and 1157.72 respectively. The number of physicians per 1000 people ranges from a minimum of 0.1 at TimorLeste to maximum 4.8 at Georgia. However, the number of inpatient beds per 1000 people is the smallest in Iran (0.1) and the highest in Japan (13.7). The average smoking prevalence of the adult male people among the studied countries is $42.2 \%$ and average primary education completion rate is $96.5 \%$ of the relevant age group.

Among the countries analysed, HALE at birth was a minimum of 53.2 years in Afghanistan and a maximum of 75.9 years in Singapore. The infant mortality rate ranged from 2.0 deaths per 1000 live births in Japan to 65.7 deaths per 1000 live births in Pakistan. On average, there were 19.9 deaths per 1000 live births in the studied countries. The scatter matrix of the input and output variables 
Open access

Table 2 Technical and scale efficiency scores of the health systems in Asian countries

\section{Country name}

CRS technical efficiency VRS technical efficiency Scale efficiency

\begin{tabular}{|c|c|c|c|c|}
\hline Afghanistan & 0.724 & 0.812 & 0.891 & 1 \\
\hline Armenia & 0.769 & 0.946 & 0.813 & -1 \\
\hline Azerbaijan & 0.660 & 0.902 & 0.732 & -1 \\
\hline Bahrain & 0.714 & 0.910 & 0.784 & -1 \\
\hline Bangladesh & 1.000 & 1.000 & 1.000 & 0 \\
\hline Bhutan & 0.775 & 0.903 & 0.858 & 1 \\
\hline Brunei Darussalam & 0.708 & 0.920 & 0.769 & -1 \\
\hline Cambodia & 0.805 & 0.916 & 0.879 & 1 \\
\hline China & 0.806 & 0.975 & 0.826 & -1 \\
\hline Cyprus & 1.000 & 1.000 & 1.000 & 0 \\
\hline Georgia & 0.751 & 0.923 & 0.813 & -1 \\
\hline India & 0.778 & 0.892 & 0.872 & 1 \\
\hline Indonesia & 0.746 & 0.904 & 0.826 & 1 \\
\hline Iran & 0.678 & 0.900 & 0.754 & -1 \\
\hline Iraq & 0.683 & 0.850 & 0.803 & 1 \\
\hline Israel & 0.874 & 0.967 & 0.904 & -1 \\
\hline Japan & 1.000 & 1.000 & 1.000 & 0 \\
\hline Jordan & 0.743 & 0.943 & 0.789 & -1 \\
\hline Kazakhstan & 0.695 & 0.882 & 0.788 & 1 \\
\hline South Korea & 0.886 & 0.972 & 0.911 & -1 \\
\hline Kuwait & 0.674 & 0.885 & 0.762 & -1 \\
\hline Kyrgyz Republic & 0.806 & 0.941 & 0.856 & 1 \\
\hline Laos & 0.818 & 0.889 & 0.920 & 1 \\
\hline Lebanon & 0.746 & 0.910 & 0.820 & 1 \\
\hline Malaysia & 0.778 & 0.927 & 0.839 & 1 \\
\hline Maldives & 0.730 & 0.944 & 0.773 & -1 \\
\hline Mongolia & 0.737 & 0.896 & 0.823 & 1 \\
\hline Myanmar & 0.743 & 0.872 & 0.852 & 1 \\
\hline Nepal & 0.861 & 0.932 & 0.924 & 1 \\
\hline Oman & 0.692 & 0.896 & 0.772 & -1 \\
\hline Pakistan & 0.827 & 0.889 & 0.930 & 1 \\
\hline Philippines & 0.779 & 0.916 & 0.850 & 1 \\
\hline Qatar & 0.677 & 0.903 & 0.749 & -1 \\
\hline Saudi Arabia & 0.624 & 0.871 & 0.716 & -1 \\
\hline Singapore & 1.000 & 1.000 & 1.000 & 0 \\
\hline Sri Lanka & 0.904 & 0.985 & 0.917 & -1 \\
\hline Syria & 0.818 & 0.848 & 0.964 & 1 \\
\hline Tajikistan & 0.856 & 0.964 & 0.888 & -1 \\
\hline Thailand & 0.791 & 0.956 & 0.828 & -1 \\
\hline Timor-Leste & 0.823 & 0.903 & 0.912 & 1 \\
\hline Turkey & 0.710 & 0.916 & 0.776 & -1 \\
\hline Turkmenistan & 0.639 & 0.859 & 0.743 & 1 \\
\hline $\begin{array}{l}\text { United Arab } \\
\text { Emirates }\end{array}$ & 0.691 & 0.889 & 0.777 & 1 \\
\hline Uzbekistan & 0.784 & 0.947 & 0.828 & -1 \\
\hline
\end{tabular}

Continued 
Table 2 Continued

\begin{tabular}{lllll}
\hline Country name & CRS technical efficiency & VRS technical efficiency & Scale efficiency & Returns to scale \\
\hline Vietnam & 0.845 & 0.996 & 0.849 & -1 \\
Yemen & 0.727 & 0.826 & 0.881 & 1 \\
\hline Mean $(\mathbf{9 5 \%} \mathbf{C l})$ & $\mathbf{0 . 7 8 0}(\mathbf{0 . 7 5 2}$ to $\mathbf{0 . 8 0 8 )}$ & $\mathbf{0 . 9 1 9}(\mathbf{0 . 9 0 5}$ to $\mathbf{0 . 9 3 3 )}$ & $\mathbf{0 . 8 4 7}(\mathbf{0 . 8 2 4}$ to $\mathbf{0 . 8 7 )}$ & - \\
\hline Median & 0.772 & 0.913 & 0.834 & - \\
Minimum & 0.624 & 0.812 & 0.716 & - \\
Maximum & 1 & 1 & 1 & - \\
\hline
\end{tabular}

CRS, constant returns to scale; VRS, variable returns to scale.

shows that inputs, for instance, increase in per-capita healthcare expenditure was associated with improved health outcomes (eg, HALE at birth and reduced infant mortality) (figure 1).

The mean CRS and VRS technical efficiency scores were 0.780 and 0.919 , respectively (table 2 ). Whereas, the mean scale efficiency score was 0.847. Considering VRS efficiency, Afghanistan has the lowest score of 0.812. Both VRS and CRS technical efficiency scores were positively correlated with per capita health expenditure, HALE at birth and negatively correlated with infant mortality (online supplementary table 1).

Out of 46 countries studied, only four (8.7\%) countries showed the maximum level of efficiency (efficiency score 1.00) in VRS and CRS technical efficiency scale. All of these four countries showed scale efficiency of 1.00 implying that these countries created the best practice frontier based on their input and output combinations. Around $39.1 \%$ (18 countries) of the studied countries showed increasing returns to scale, $52.2 \%$ countries (24 countries) showed decreasing returns to scale and four efficient countries showed CRS production function of their health systems.

More than half of the countries (30 countries) had VRS efficiency, and five countries had CRS efficiency greater than $90 \%$ (online supplementary figure 1 ).

\section{Result from Tobit regression and bootstrap analysis for associated factors with the inefficiency}

Tobit regression and smoothed bootstrap were used to relate VRS efficiency scores to two health service production variables and four environmental variables in two separate models (table 3). Negative associations with the inefficiency scores in the Tobit model represent positive relation of health system efficiency with the explanatory variables. However, positive associations with the explanatory variables in the smoothed bootstrap model represent positive relations of the health system efficiency with the explanatory variables.

Physician density, income status of countries and smoking prevalence among males exhibited statistically insignificant associations with the health system efficiency in the both models. The density of bed (more than three to fewer than or equal to five) had a significantly negative association with the inefficiency scores (ie, positive association with the efficiency) compared with less than one bed density category. Countries having more than one and less than or equal to three bed density had no significant association with the inefficiency scores. However, after the bootstrapping, this category became significant and the significance level increased for the rest two categories (ie, more than three and less than or equal to five bed density and more than five bed density). The association of bed density in the both models indicates that sample countries with less than one bed density have lower technical efficiency of their health systems. Furthermore, the primary education completion rate was significantly negatively associated with the inefficiency score in the Tobit model, which indicates that countries with higher percentage of primary education completion rate have higher health system efficiency. Similar association was observed in the bootstrap model. In case of population density, we found in the both models that countries having more than 200 population per square kilometre were more efficient in their health system efficiency compared with the countries with less than or equal to 100 population per square kilometre.

\section{Sensitivity of the efficiency scores}

We conducted sensitivity analysis using various combinations of input and output variables. In all of these cases, the average of the efficiency scores varied from 0.812 to 0.936. The most sensitive combination was found while using the HALE at age 60 years as the outcome variable. The efficiency score changed from 0.919 (main model) to 0.812 (considering input as HALE at age 60 years) (figure 2).

In table 4, mean efficiency scores are presented by the income categories of the countries. The highest mean VRS technical efficiency were observed for high-income countries $(0.934 ; 95 \%$ CI 0.905 to 0.963$)$, followed by upper middle-income $(0.914 ; 95 \%$ CI 0.894 to 0.935$)$, and low and lower middle income countries (0.913; $95 \%$ CI 0.891 to 0.935$)$. If all the health systems operated at maximum efficiency at their given input level, the high-income, upper middle-income, low-income and lower middle-income countries could improve their 


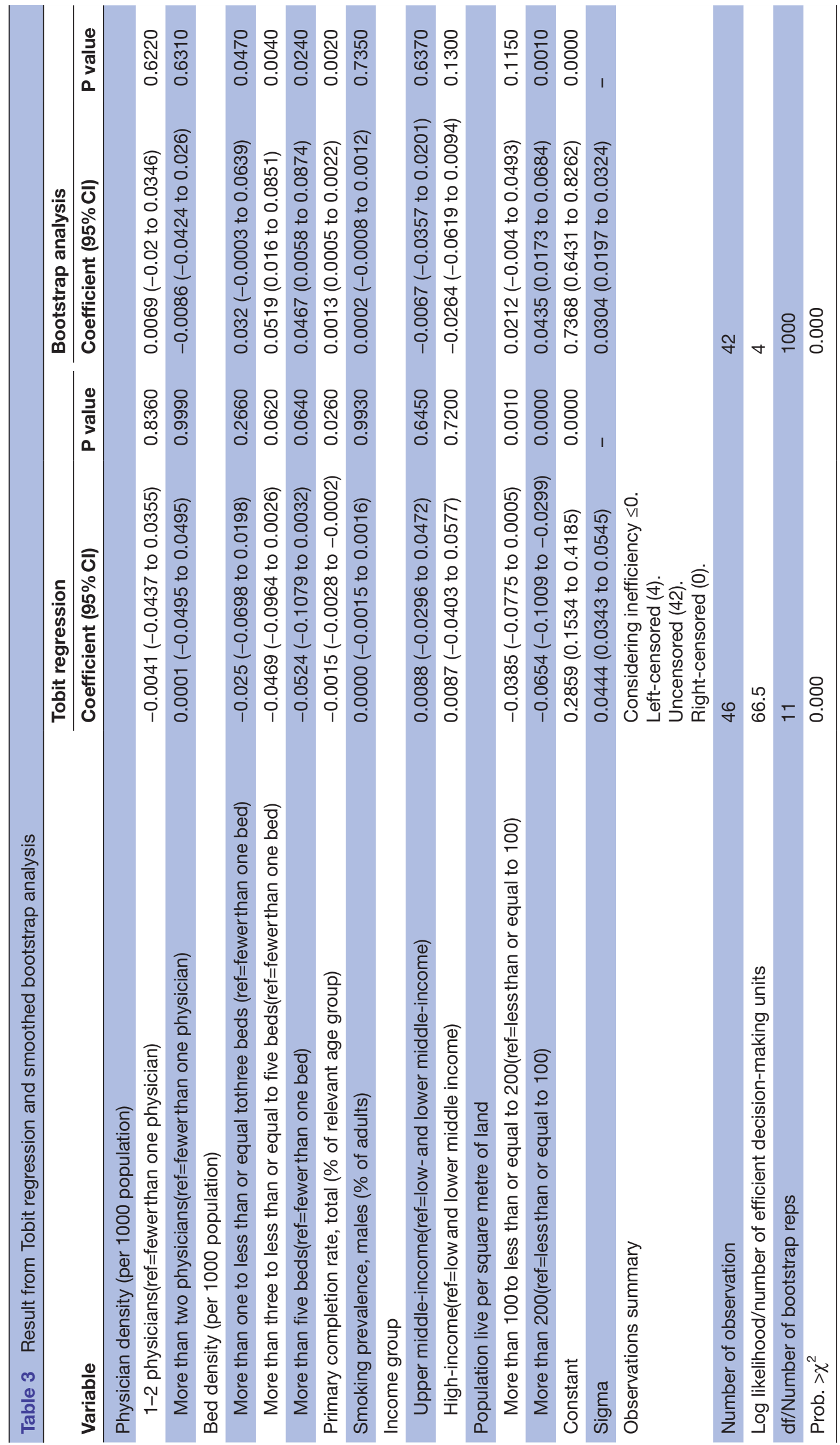




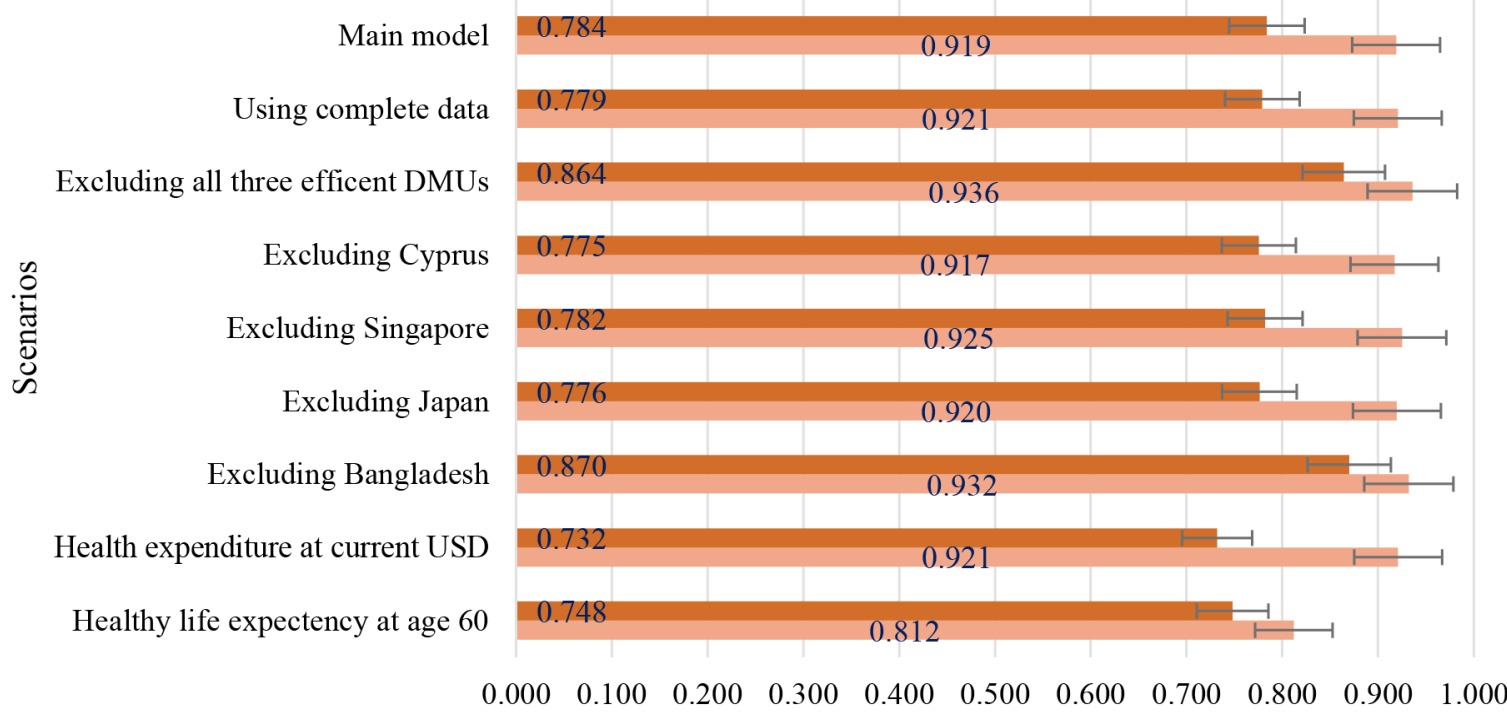

Technical efficiency score

๓CRS technical efficiency $\quad$ VRS technical efficiency

Figure 2 Results from the sensitivity analysis of efficiency scores. CRS, constant returns to scale; DMUs, decision-making units; VRS, variable returns to scale.

health system outcome (eg, HALE at birth and reduce infant mortality) by $6.6 \%, 8.6 \%$ and $8.7 \%$ respectively.

\section{DISCUSSION}

The main findings of this paper demonstrated that about 91.3\% of the studied Asian countries are technically inefficient with respect to using healthcare systems resources (using a proxy of per capita health expenditure). The study findings showed that among the studied Asian countries, the majority of the efficient countries belonged to the high-income group (Cyprus, Japan and Singapore). Only one country belonged to the low- and lower middle-income group (Bangladesh). Among the 46 countries studied, only four countries (Bangladesh, Japan, Singapore and Cyprus) showed CRS efficiency, indicating that they were operating

Table 4 Mean efficiency scores according to income level of Asian countries

VRS technical efficiency Percentage of output can be improved in VRS technical

\begin{tabular}{|c|c|c|c|}
\hline Income groups & Mean & $95 \% \mathrm{Cl}$ & efficiency, \% \\
\hline $\begin{array}{l}\text { Low income } \\
\text { and lower } \\
\text { middle income }\end{array}$ & 0.913 & (0.891 to 0.935 ) & 8.7 \\
\hline $\begin{array}{l}\text { Upper middle } \\
\text { income }\end{array}$ & 0.914 & (0.894 to 0.935$)$ & 8.6 \\
\hline High income & 0.934 & (0.905 to 0.963 ) & 6.6 \\
\hline
\end{tabular}

VRS, variable returns to scale. at their most efficient level. Of the 14 high-income countries studied, nine countries $(75.0 \%)$ had health system production at decreasing returns to scale. This implies that although the highest number of efficient countries belonged to the high-income group, a large number of these countries' health system production had more resources than the ideal situation. A similar situation was observed for the upper middle-income countries. Of the 13 countries, 10 $(76.9 \%)$ had decreasing returns to scale. Only $5(23.8 \%)$ out of 21 low-income and lower middle-income countries were producing at decreasing returns to scale. Although these low-income and lower middle-income countries are not efficient, most of their production follows increasing returns to scale.

It was observed that the average of the efficiency scores increased from the low-income and lower middle-income countries to high-income countries. An important policy implication of this study could be that the technically inefficient low-income and lower-middle income countries on average can improve their health systems outcome by $8.7 \%$, middle-income country by $8.6 \%$ and high-income country by $6.6 \%$ using the existing levels of per-capita health expenditure. An international study found a similar conclusion that health systems performance is most efficient in the developed countries according to simple efficiency scores. ${ }^{64}$

The overall healthcare efficiency in different countries varied considerably. ${ }^{6566}$ Among the low-income and lower middle-income countries studied, one country demonstrated the most efficient health systems (Bangladesh). This country has both technical and scale efficient health systems, like the high-income countries (Japan, Singapore, and Cyprus). ${ }^{67} \mathrm{~A}$ possible reason for the high efficiency of this 
country could be a focus on infant mortality and child health as prioritised in past Millennium Development Goals and in current Sustainable Development Goals agendas, which relates to the outcome variables used in this study.

The DEA result showed that more than $60 \%$ of the low-income and lower middle-income countries had health system efficiency greater than $90 \%$. This result implies that these countries produce good health at low cost and therefore make good use of health systems resources. ${ }^{68}$ This result suggests that it is possible for countries to have a high-efficiency score with poor health outcomes because of their low expenditure on resources and increasing returns to scale production function. In other words, given their moderate consumption of inputs and challenging social environments, these countries can achieve good health outcomes, relative to the other countries. Similar findings were observed for Mexico and Turkey relative to other countries in a study of the OECD countries. ${ }^{39}$ It should be noted that this study only used per-capita health expenditure and there are other factors that influence health outcomes as well. For example, differences in life expectancy and infant mortality between populations can be due to lifestyles, preferences ${ }^{566970}$ social class, occupation ${ }^{71}$ and environmental factors. ${ }^{72}{ }^{73} \mathrm{On}$ a more macroscopic level, the results could also be impacted by a variety of contextual factors among countries such as different political institutions, economic landscapes, healthseeking behaviour patterns and burden of diseases among other things. However, in this study, we attempted to address by including variables addressing the number of physicians, number of inpatient beds and population density, along with two environmental factors namely primary completion rate of relevant age group and smoking prevalence among the adult male population to take into consideration some of this variation. The results showed that more than three and less than five beds per 1000 population significantly influenced the efficiency score. A low number of beds cannot serve a large proportion of the population and therefore the systems may be inefficient. Similarly, a high number of beds may often be left unused and make the health systems inefficient. The countries having more than 200 people living per square kilometre had a higher level of efficiency in their health systems.

A limitation of DEA methodology is that it works in a deterministic way, meaning that the results entirely depend on the numeric values in the dataset. As the DEA approach compares DMUs, the number and nature of DMUs in the data set can noticeably change the results. For example, if a more efficient country is added to the dataset, it would move the frontier, causing some of the efficiency scores of other countries to fall. This is a key aspect of the methodology used.

Additionally, it is important to note that the use of a different set of variables might have generated different conclusions. In the future, if additional data become available for a larger number of countries in the region, the number of variables analysed could be increased to include an understanding with a greater degree of complexity in health system efficiency.
Another data limitation is the comparability of health expenditures among the Asian countries. While recognising that it is not possible to solve the inherent issues, we made an attempt to minimise it. Since the actual amount of healthcare expenditure across different countries may not be comparable due to the difference in purchasing power parity across countries, we used health expenditures as constant of 2011 in PPP as an input in the DEA model. ${ }^{39}$ Also, when we included health expenditure at current USD per capita as an input in the DEA model, we found that the efficiency score did not change significantly.

We applied sensitivity analysis in an attempt to overcome these limitations (figure 2). Our results were consistent while using several combinations of inputs and outputs variables, which is reassuring and strengthens the findings from this study.

\section{CONCLUSIONS}

This study provides an empirical picture of the technical efficiency of the healthcare systems of 46 Asian countries. The study shows that inefficiency exists in the healthcare systems of most of the countries studied; however, the results point to three high-income and one lower middle-income country, which efficiently used healthcare systems resources. The interpretation of the inefficient countries identified through this study is that they can improve health outcomes using the current level of per-capita health expenditure. These countries could use these results to direct their attention to benchmarking their health systems within their regional or another comparative group in order to understand their health system performance in a more detailed way. This study addresses the need to understand efficiency issues, as well as potentially identify good examples of countries that efficiently allocate and use resources to make their healthcare systems more technically efficient. It narrows a gap in the literature as there are few countries studying healthcare efficiency in Asia and looking comparatively in this manner.

\section{Author affiliations}

${ }^{1}$ Health Systems and Population Studies Division, International Centre for Diarrhoeal Disease Research, Bangladesh (icddr,b), Dhaka, Bangladesh

${ }^{2}$ Liverpool School of Tropical Medicine, Liverpool, United Kingdom

${ }^{3}$ Health Economics and Policy Research Group, Department of Learning, Informatics, Management and Ethics (LIME), Karolinska Institutet, Stockholm, Sweden

${ }^{4}$ Department of Social Policy, London School of Economics and Political Science, London, United Kingdom

${ }^{5}$ Institute for Social Science Research, The University of Queensland, Indooroopilly, Queensland, Australia

${ }^{6}$ Health, Nutrition Population Programme, BRAC, Dhaka, Bangladesh

Acknowledgements icddr,b is thankful to the Governments of Bangladesh, Canada, Sweden and the UK for providing core/unrestricted support. The authors would like to thank The World Bank for providing open access to the World Development Indicators database and the World Health Organization for their data repository.

Contributors SA, MZH and MM contributed to conceptualising the research idea, study design, literature search, data extraction and analysis, data interpretation and writing the manuscript. MWA, FD, SMH, MMH, MTI and JAMK contributed to writing, reviewing and revising the manuscript. All authors read and approved the final manuscript. 
Funding The authors have not declared a specific grant for this research from any funding agency in the public, commercial or not-for-profit sectors.

Competing interests None declared.

Patient consent for publication Not required

Provenance and peer review Not commissioned; externally peer reviewed.

Data sharing statement Data were extracted from the World Bank Open Data repository for the 'World Development Indicators' and for World Health Organization Global Health Observatory. The following link was used to extract Excel format of the indicators https://data.worldbank.org/ and http://www.who.int/gho/en/.

Open access This is an open access article distributed in accordance with the Creative Commons Attribution Non Commercial (CC BY-NC 4.0) license, which permits others to distribute, remix, adapt, build upon this work non-commercially, and license their derivative works on different terms, provided the original work is properly cited, appropriate credit is given, any changes made indicated, and the use is non-commercial. See: http://creativecommons.org/licenses/by-nc/4.0/.

\section{REFERENCES}

1. Melorose J, Perroy R, Careas S. World population prospects. United Nations, 2015;1:587-92

2. Asandului L, Roman M, Fatulescu P. The Efficiency of Healthcare Systems in Europe: a data envelopment analysis approach. Procedia Econ Financ 2014;10:261-8.

3. Organization WH. Health at a Glance: Asia/Pacific 2014 Measuring Progress towards Universal Health Coverage: Measuring Progress towards Universal Health Coverage: OECD Publishing, 2014.

4. Vargas V, Begum T, Ahmed S, et al. Bangladesh - Fiscal space for health: Toward the Fiscal Space for Health in Bangladesh. Washington D.C, 2016.

5. The World Bank. World Development Indicators. Washington, DC: The World Bank, 2017

6. Jacobs D. Low public expenditures on social welfare: do East Asian countries have a secret? Int J Soc Welf 2000;9:2-16.

7. van Doorslaer E, O'Donnell O, Rannan-Eliya RP, et al. Effect of payments for health care on poverty estimates in 11 countries in Asia: an analysis of household survey data. Lancet 2006;368:1357-64

8. WHO. Intercountry Cooperation : cross-border Control of Priority Communicable Diseases. New Delhi, 2004.

9. Chisholm D, Evans DB. Improving health system efficiency as a means of moving towards universal coverage. Geneva: World Health Organization, 2010.

10. Schwartz WB, Mendelson DN. Eliminating waste and inefficiency can do little to contain costs. Health Aff 1994;13:224-38.

11. Smith PC. Measuring health system performance. Eur J Health Econ 2002;3:145-8.

12. European Commission's DG for Employment SA \& I. Employment, Social Affairs \&amp; Inclusion - European Commission. 2017.

13. Medeiros J, Schwierz C. Efficiency estimates of health care systems in the EU. 2015;3187.

14. Papanicolas I, Smith PC. Health System Performance Comparison: An Agenda for Policy, Information and Research. European Observatory on Health Systems and Policies. 1st edn. New York: Open University Press, 2013:1-417.

15. Chattopadhyay S, Ray SC. Technical, scale, and size efficiency in nursing home care: a nonparametric analysis of Connecticut homes. Health Econ 1996:5:363-73.

16. Shroff HE, Gulledge TR, Haynes KE, et al. Siting efficiency of longterm health care facilities. Socioecon Plann Sci 1998;32:25-43.

17. Hollingsworth $B$, Parkin D. The efficiency of the delivery of neonatal care in the UK. J Public Health Med 2001;23:47-50.

18. Giuffrida $A$, Gravelle $H$. Measuring performance in primary care: econometric analysis and DEA. Appl Econ 2001;33:163-75.

19. Chang H-hui. Determinants of Hospital Efficiency: the Case of Central Government-owned Hospitals in Taiwan. Omega 1998;26:307-17.

20. Wan TT, Hsu N, Feng RC, et al. Technical efficiency of nursing units in a tertiary care hospital in Taiwan. J Med Syst 2002;26:21-7.

21. Hollingsworth B, Dawson PJ, Maniadakis N. Efficiency measurement of health care: a review of non-parametric methods and applications. Health Care Manag Sci 1999;2:161-72.

22. Dimas G, Goula A, Soulis S. Productive performance and its components in Greek public hospitals. Operational Res 2012;12:15-27.
23. Zere E, Mcintyre D, Addison T. Technical efficiency and productivity of public sector hospitals in three South African Provinces. South African J Econ 2005;69:336-58.

24. Zhang L, Cheng G, Song S, et al. Efficiency performance of China's health care delivery system. Int $J$ Health Plann Manage 2017;32:254-63.

25. Allin S, Grignon M, Wang L. The determinants of efficiency in the Canadian health care system. Health Econ Policy Law 2016;11:39-65.

26 Kim Y, Kang M. The measurement of health care system efficiency: cross-country comparison by geographical region. The Korean Journal of Policy Studies 2014;29:21-44.

27. Cheng Z, Tao H, Cai M, et al. Technical efficiency and productivity of Chinese county hospitals: an exploratory study in Henan province, China. BMJ Open 2015;5:e007267.

28. Jat TR, Sebastian MS. Technical efficiency of public district hospitals in Madhya Pradesh, India: a data envelopment analysis. Glob Health Action 2013;6:21742.

29. Hussey PS, de Vries H, Romley J, et al. A systematic review of health care efficiency measures. Health Serv Res 2009;44:784-805.

30. WHO, Organization WH. Health in Asia and the Pacific. New Delhi: WHO, 2008:561.

31. WHO. Global Health Expenditure Database: World Health Organization, 2017.

32. United Nation. United Nations Statistics Division- Standard Country and Area Codes Classifications: United Nation, 2016. (Cited 12 Dec 2016).

33. Anderson GF, Hurst J, Hussey PS, et al. Health spending and outcomes: trends in OECD countries, 1960-1998. Health Aff 2000;19:150-7.

34. Färe R, Grosskopf S, Lindgren B, et al. Productivity growth in healthcare delivery. Med Care 1997;35:354-66.

35. Grubaugh SG, Santerre RE. Comparing the performance of health care systems: an alternative approach. South Econ $J$ 1994;60:1030-42.

36. Morris S, Devlin N, Parkin D, et al. Economic analysis in health care. 2nd edn. Chichester: John Wiley \& Sons, Ltd, 2012:292.

37. Kirigia JM, Sambo LG, Renner A, et al. Technical efficiency of primary health units in Kailahun and Kenema districts of Sierra Leone. Int Arch Med 2011;4:15.

38. Wranik D. Healthcare policy tools as determinants of health-system efficiency: evidence from the OECD. Health Econ Policy Law 2012;7:197-226.

39. Retzlaff-Roberts D, Chang CF, Rubin RM. Technical efficiency in the use of health care resources: a comparison of OECD countries. Health Policy 2004;69:55-72.

40. Spinks J, Hollingsworth B. Cross-country comparisons of technical efficiency of health production: a demonstration of pitfalls. Appl Econ 2009;41:417-27.

41. Charnes A, Cooper WW, Rhodes E. Measuring the efficiency of decision making units. Eur J Oper Res 1978;2:429-44.

42. Banker RD, Charnes A, Cooper WW. Some Models for Estimating Technical and Scale Inefficiencies in Data Envelopment Analysis. Manage Sci 1984;30:1078-92.

43. Achoki T, Hovels A, Masiye F, et al. Technical and scale efficiency in the delivery of child health services in Zambia: results from data envelopment analysis. BMJ Open 2017;7:1-12.

44. WHO. The world health report: health systems financing: the path to universal coverage. Geneva: World Health Organisation, 2010.

45. Cooper W, Seiford L, Tone K. Data envelopment analysis a comprehensive text with models, applications, references and DeaSolver software. New York: Springer, 2007.

46. Masiye F. Investigating health system performance: an application of data envelopment analysis to Zambian hospitals. BMC Health Serv Res 2007;7:58.

47. Kirigia JM, Emrouznejad A, Gama Vaz R, et al. A comparative assessment of performance and productivity of health centres in Seychelles. Int J Product Perform Manag 2007;57:72-92.

48. Osei D, d'Almeida S, George MO, et al. Technical efficiency of public district hospitals and health centres in Ghana: a pilot study. Cost Eff Resour Alloc 2005;3:9.

49. Ramalho EA, Ramalho JJS, Henriques PD. Fractional regression models for second stage DEA efficiency analyses. J Product Anal 2010;34:239-55

50. McDonald J. Using least squares and tobit in second stage DEA efficiency analyses. Eur J Oper Res 2009;197:792-8.

51. Simar L, Wilson PW. Estimation and inference in two-stage, semi-parametric models of production processes. J Econom 2007;136:31-64.

52. Afonso A, St. Aubyn M. Assessing health efficiency across countries with a two-step and bootstrap analysis. Appl Econ Lett 2011;18(15):1427-30. 
53. Zere E. Hospital Efficiency in Sub-Saharan Africa Evidence. Helsinki, 2000.

54 Newhouse JP, Friedlander LJ. The relationship between medical resources and measures of health: some additional evidence. J Hum Resour 1980;15:200-18.

55 Starfield B. Health services research: a working model. N Engl J Med 1973;289:132-6.

56 Johansson SE, Sundquist J. Change in lifestyle factors and their influence on health status and all-cause mortality. Int J Epidemiol 1999;28:1073-80.

57 Or Z. Determinants of health outcomes in industrialised countries: A pooled, cross-country, time-series analysis. OECD Economic Studies 2000;30:53-77.

58. Badunenko O, Tauchmann H. SIMARWILSON: Stata module to perform Simar \& Wilson (2007) efficiency analysis:Boston College Department of Economics. 2016 https://ideas.repec.org/c/boc/ bocode/s458156.html

59. McCallion G, Colin Glass J, Jackson R, et al. Investigating productivity change and hospital size: a nonparametric frontier approach. Appl Econ 2000;32:161-74.

60 Alirezaee MR, Howland M, van de Panne C. Sampling size and efficiency bias in data envelopment analysis. Journal of Applied Mathematics and Decision Sciences 1998;2:51-64.

61. Hollingsworth B, Peacock SJ. Efficiency measurement in health and health care. 1st edn. New York: Routledge, 2008.

62. Golany B, Roll Y. An application procedure for DEA. Omega 1989;17:237-50.

63. Smith P. Model misspecification in data envelopment analysis. Ann Oper Res 1997;73:233-52.
64. Grosskopf S, Self S, Zaim O. Estimating the efficiency of the system of healthcare financing in achieving better health. Appl Econ 2006;38:1477-88.

65 Union E. Comparative efficiency of health systems, corrected for selected lifestyle factors Final report: European Commision, 2014

66. Joumard I, Andre C, Nicq C. Health Care Systems: Efficiency and Institutions. SSRN Electronic Journal 2010:1-132.

67. Koblinsky M, Anwar I, Mridha MK, et al. Reducing maternal mortality and improving maternal health: Bangladesh and MDG 5. J Health Popul Nutr 2008;26:280-94.

68. Balabanova D, Mills A, Conteh L, et al. Good health at low cost 25 years on: lessons for the future of health systems strengthening. Lancet 2013;381:2118-33.

69. Colditz GA, Atwood KA, Emmons K, et al. Harvard report on cancer prevention volume 4: Harvard Cancer Risk Index. Cancer Causes and Control 2000;11:477-88.

70. Laaksonen M, McAlister AL, Laatikainen T, et al. Do health behaviour and psychosocial risk factors explain the European east-west gap in health status? Eur J Public Health 2001;11:65-73.

71. Hart CL, Smith GD, Blane D. Inequalities in mortality by social class measured at 3 stages of the lifecourse. Am J Public Health 1998;88:471-4.

72. Cohen DA, Mason K, Bedimo A, et al. Neighborhood physical conditions and health. Am J Public Health 2003;93:467-71.

73. Jerrett M, Eyles J, Cole D. Socioeconomic and environmental covariates of premature mortality in Ontario. Soc Sci Med 1998;47:33-49. 